\title{
Expertise and aging: maintaining skills through the lifespan
}

\author{
Sean Horton • Joseph Baker • Jörg Schorer
}

Received: 8 July 2007 / Accepted: 5 March 2008 / Published online: 3 April 2008

(C) European Group for Research into Elderly and Physical Activity (EGREPA) 2008

\begin{abstract}
As lifespan continues to increase in many developed countries, so too does the age at which we see extraordinary achievements from older adults. Examples from running, golf, and other domains continue to redefine what is possible as we age. Evidence suggests, however, that progression through adulthood is associated with a dramatic decline in all manner of physical and cognitive abilities, from physiological capacities (e.g., VO2 max) to cognitive and perceptual functions (e.g., IQ scores, reaction time). In the face of such precipitous decline in specific abilities, how do we account for maintenance of skilled performance and expertise amongst those supposedly well along the age-decline curve? Expert performers are seem-
\end{abstract}

This manuscript has been supported by a post-doctoral fellowship from the Social Science and Humanities Research Council of Canada (SSHRC no. 756-2007-0212) to the first author, by a standard research grant from the Social Sciences and Humanities Research Council of Canada (SSHRC Grant no. 410-04-1207) to the second author, and by the German Federal Institute for Sport Science to the third author.

\footnotetext{
S. Horton $(\bowtie)$

Department of Kinesiology, University of Windsor,

Windsor, Canada

e-mail: hortons@uwindsor.ca

J. Baker

School of Kinesiology and Health Science, York University,

Toronto, Canada

J. Baker

Carnegie Research Institute, Leeds Metropolitan University, Leeds, UK

J. Schorer

Institute for Sport Science,

Westfälische Wilhelms-University Münster,

Münster, Germany
}

ingly able to sustain high levels of achievement in the face of an overall deterioration in general capacities. Moreover, experts maintain this performance in spite of reduced involvement in their field. There are three primary explanations for the ability of experts to maintain superior performance in spite of an overall decline in abilities: (a) preserved differentiation, (b) compensation, and (c) selective maintenance. Overall, research into the high achievements of older adults may reveal a great deal with respect to skill preservation and how to best counter age-related decline.

Keywords Aging $\cdot$ Performance $\cdot$ Skill acquisition · Skill maintenance

\section{Introduction}

In an aging society, questions concerning the preservation of skills and abilities take on increasing urgency and importance. Researchers have reported on the numerous agerelated declines across many aspects of cognitive and physical functioning [6], which might understandably create some angst amongst a cohort of baby boomers about to embark on their senior years. For example, the decline in IQ scores is just over one standard deviation, or 16 points, from the age of 25 to 65 [25]. Choice reaction time slows by $60 \%$ from the age of 20 to age 60 [38]. Overall, the research shows that normal aging takes a significant toll on the speed and efficiency of cognitive, perceptual, and psychomotor functions (Krampe and Charness [28]).

Yet, as Horn and Masunaga [25] note, this cascade of decline seen in laboratory settings is often at odds with what we experience personally and what we see in society. In many of our major institutions, in universities, in govern- 
ment, and in the business world, people holding positions of leadership and responsibility are usually old enough to be well along the age-decline curve. Scholars, writers, and musicians, all from fields that we associate with a high degree of intellectual functioning, continue to make contributions and perform at high levels well into years that the research suggests should be associated with significant cognitive deterioration. In addition, increasing participation in masters athletics, combined with remarkable individual performances of certain athletes are prompting researchers to re-evaluate what is possible in the sports world as we age [44].

Given the disparity between the research findings and the individual examples so prevalent in society, Rabbit [37] may have posed the query most appropriately. In view of the deterioration of memory and perceptual-motor performance with advancing age, the right kind of question may well be not 'why are old people so bad at cognitive tasks,' but rather, 'how, in spite of growing disabilities, do old people preserve such relatively good performance?' (p. 263).

Indeed, how do we account for maintenance of skilled performance and expertise in many athletic and other domains in the face of a general deterioration in overall abilities? Research into the high achievements of older adults may reveal a great deal with respect to skill preservation and how to best counter age-related decline.

\section{Developing expertise}

Francis Galton is widely attributed for launching the scientific investigation into high achievement [25]. Galton [20] highlighted three primary components to achieving excellence, namely innate capacity, zeal, and the power to work hard. Initial research into Galton's assertions focused on the first of these components - innate capacity — primarily through attempts to determine a relatively fixed and stable notion of a person's intellectual capacities that provided the foundation for building complex skills. In analyzing some of the highest achievers in human history, this notion of general, stable, innate capacities does have its intuitive appeal. At the tender age of four, Wolfgang Mozart was already composing music. By age six he had acquired considerable fame and was performing all across Europe with kings and queens as his audience [26]. Yet commentators have noted that while Mozart's achievements were undoubtedly remarkable for such a young age, his early works were not extraordinary compared to other adult musicians of the time. In fact, it was not until Mozart was in his early 20 s that he created work was that was considered completely original and truly exceptional, irrespective of his age [26].

A more contemporary example from the sporting world is Tiger Woods. Woods showed the same kind of precociousness in golf that Mozart showed in music. Woods had been featured on television shows twice by the time he was 5 years old [35]. His record as a junior golfer is unmatched; in one season, he emerged the victor in each of the 33 tournaments that he entered. Woods started competing against professionals at the age of 16 . He was 20 , however, before he started winning at the professional level, and 21 before he achieved the number one ranking in the world-a full 19 years after his first television appearance [35]. This lengthy apprenticeship, even amongst those considered to be virtually without peer in their field, is common across many domains.

Simon and Chase [45] postulated that a minimum of 10 years was required to achieve expertise in the game of chess. Ericsson, Krampe, and Tesch-Römer [19] drew similar conclusions in their examination of musicians, and research into various sports has supported the 10-year time frame (i.e., [13, 23, 24]). The long apprenticeship that appears to be required of even the most "talented" has resulted in a focus more recently on the latter two of Galton's premises, those of zeal and the capacity for hard work ${ }^{1}$.

Ericsson et al.'s [19] analysis of the practice habits of musicians demonstrated that it was the nature of the practice, and not just the sheer number of hours accrued, that was central to continued development. Ericsson [16] insisted that mere duration was not a perfect predictor of expertise and that practice without full concentration might actually impair performance. Therefore, the best gauge of expertise in any domain was the number of hours of "deliberate practice" that have been accumulated. Ericsson et al. [19] defined deliberate practice as activity that required substantial effort, was not inherently enjoyable, was highly relevant, and would result in maximal improvement in performance. Furthermore, engagement in such activities could only occur for a limited amount of time per day due to fatigue and burnout considerations.

While researchers investigating high performance in sport have generally agreed with the amount, and type, of practice required to achieve expertise, differences have emerged with respect to the specifics. While Ericsson's notion of deliberate practice for musicians emphasized practice alone, Helsen et al. [22] stated that for the theory to be applied in a meaningful way to team sports it must be expanded from practice alone to include practice with others and team practice. In addition, Baker et al. [2] found that the amount of time required to achieve expertise was

\footnotetext{
${ }^{1}$ Although Ericsson and others have emphasized the role of training and practice in skill development and maintenance, this does not rule out biological or genetic factors. Recent research (Davids \& Baker, 2007) suggests that there is a critical and pervasive interaction between biological and environmental factors in determining human performance.
} 
highly variable. Part of this, as the authors acknowledge, may depend on the nature of the sport, specifically the length of time it has been played and the number of people globally that partake in the activity. Similarly, Ericsson [16] noted that very tall basketball players and memory experts have reached world-class levels in less than 10 years of training.

\section{Achieving and maintaining peak performance}

While the amount of time it takes to become an expert can vary depending on the discipline, the age at which people achieve expertise will also vary by the type of activity. Lehman [31] launched one of the first major investigations into age and achievement by detailing the age of peak productivity across more than 50 disciplines and professions, including athletic endeavors. Schultz and Curnow [40] expanded on this work by surveying different sports ranging from those requiring primarily speed and power (i.e., sprinting, jumping, and swimming) to those placing more demands on cognitive and motor factors (i.e., golf, baseball). The authors found that, while dramatic performance improvements occurred across the 20 century in all activities, the age at which athletes reached their highest level of performance remained remarkably stable. In explosive sports, those depending more heavily on reaction time and raw power (e.g., sprinting) athletes consistently peaked in their early 20s. For sports like golf and baseball that were more cognitive in nature and required greater precision and control, peak performance occurred in the late 20 s or early 30s. Schultz and Curnow [40] speculated that biological factors define both the lower and upper age limits within which peak performance can occur. For sports that rely more heavily on complex motor skills the window of peak performance is generally later in life, and consists of a longer time frame.

This raises interesting questions as to how long one can maintain peak performance in the face of inevitable biological changes that occur with advancing age. Bortz and Bortz [6] postulated a $0.5 \%$ yearly decline from the age of 35, based on their analysis of running, rowing, and swimming events. The authors compared this rate of decline to rates of degeneration in other bodily systemsprimarily VO2 max, but also systems as varied as DNA repair, cerebral metabolism, number of muscle cells, and even the rate of nail growth. As the deterioration in each of these systems was approximately $0.5 \%$ per year, Bortz and Bortz concluded that this rate may represent a basic biomarker of the aging process.

Other examinations of athletic events have determined a similar rate of decline, although specific rates can differ depending on how the data are measured. Starkes et al. [44] compared cross-sectional examinations of performance, which typically consists of large numbers of participants in different age groups, to longitudinal data, where individuals are followed over a certain length of time. Starkes et al. [44] found that overall, longitudinal examinations of athletic performance show a less dramatic and more gradual rate of decline with aging. A review of their data specific to the $1,500 \mathrm{~m}$ and $10 \mathrm{k}$ running times of Master track athletes showed annual declines in the range of $0.7-1 \%$ when measured cross-sectionally, compared to annual declines of $0.37-0.47 \%$ based on longitudinal analysis [3].

Sports that are less reliant on physiological components and are more cognitive in nature seem to show greater resistance to the effects of age. Baker et al. [4] examined the performance of elite professional golfers from the age of 35 through to age 60 . The rate at which performance deteriorated was substantially less than the $0.5 \%$ predicted by Bortz and Bortz [6]. The golfers showed a decline of just $0.07 \%$ per year from age $35-50$. This decline accelerated to $0.25 \%$ per year from ages $51-60$, although even this accelerated rate was just half of that predicted by Bortz and Bortz [6]. In a follow-up study of professional golfers, Baker et al. [3] examined the components of golf performance and found that golf tasks that emphasized power and strength (i.e., driving distance) declined at a faster rate than tasks emphasizing fine motor skill; however, the rate of decline was still significantly less than $0.5 \%$ (i.e., $0.23 \%$ per year for driving distance and $0.11 \%$ per year for putting).

Preliminary results from a recent study by Schorer and Baker [41] suggest that perceptual performance of former world-class handball goalkeepers is maintained despite advancing age. The ability to anticipate an opponent's actions through the use of advanced visual information, considered a hallmark of perceptual expertise, was found to be stable over time. Of interest was the fact that performance was maintained in the absence of specific physical practice; the older goalkeepers' involvement in the game was limited to that of goalkeeper coach or team manager. The authors speculated that skills such as the capacity to identify critical sources of information from an opponent (e.g., being able to predict a shot's direction through arm and racket placement in tennis), may be quite stable despite advancing age and lack of continued practice in the domain.

Studies in other cognitive/motor domains have found performance to be only marginally affected by age. Salthouse [38] examined 74 typists (ages 19-72) in two separate studies on a number of different tasks designed to gauge both typing specific skills along with more general measures of perceptual-motor and cognitive efficiency. Salthouse found that performance of typists remained virtually unchanged across the adult life span; the average 
interkey interval in typing was nearly identical for older and younger typists. This in spite of the fact that choice RT, rate of tapping, and digit-symbol substitution rate, all thought to be important components of typing performance, slowed with age. Salthouse established that older typists had increased their eye-hand span, and he suggested that this greater anticipation of impending characters is the mechanism by which older typists maintain their high levels of performance.

Similarly, Charness [8] found that in an examination of chess players, the quality of chess moves by older adults did not diminish with age, in spite of the fact that older experts engaged in a less extensive search process. Charness analyzed the think-aloud protocols of 34 participants for each of four chess positions. He speculated that older players forgo the extensive verification phase once they have chosen their move, which enables them to end the search process earlier.

The relative stability of performance amongst experts is also evident in music. Krampe and Ericsson [29] measured young and old expert pianists along with young and old amateurs on a variety of skills, those both specific to piano and those more general in nature. The participants were also asked to recall the hours dedicated to deliberate practice over the course of their careers. The results mirrored those found in chess and typing, in the sense that age did not have a deleterious effect on piano performance for the experts. For the general measures of processing speed, like choice RT and digit symbol substitution, both the older experts and the older amateurs showed normal age-related decline. For those tasks specific to piano expertise, however, older amateurs and experts diverged in their results. Older amateurs showed the negative effects of age on these tasks just as they did with the measures of general processing, while experts displayed no decline in these piano-specific abilities. Krampe and Ericsson hypothesized that the expert pianists' continued engagement in deliberate practice prevented deterioration of their pianospecific skills. While older experts were practicing significantly less than the younger experts $(10.8 \mathrm{~h} /$ week of deliberate practice vs. $26.7 \mathrm{~h}$ ) the older amateurs were investing just $1.2 \mathrm{~h}$ per week.

\section{Moderating the decline}

There are three primary explanations for the ability of experts to maintain superior performance in spite of an overall decline in abilities: (a) preserved differentiation, (b) compensation, and (c) selective maintenance. The preserved differentiation (or general factor) account asserts that the ultimate level of achievement of any individual is determined by innate general factors and capacities. Experts have always had superior abilities; these abilities are fixed, existed prior to the development of expertise in the domain, and account for the superior performance at every stage in the expert's career. IQ measurements and its correlation with academic achievement, job training, and initial job performance provide support for the general factor account [39]. Of particular relevance to the development of expert performance, however, the correlation between IQ and job performance weakens the longer one has been involved in the domain [28].

In addition, the notion of domain specificity, where an expert exhibits superiority on structured activities but shows no advantage in unstructured activities within the domain, counters the theory that innate, hardwired skills account for expertise. Initially demonstrated in chess [14, 45], these findings have been replicated in fields as varied as music [42], physics [9], medicine [15], and a number of sports (e.g., $[1,12])$. While it is certainly tempting to assert that expert athletes are blessed with better stereoacuity, or faster reaction time, research findings provide no conclusive evidence that experts are genetically any different than the rest of the population [43].

Evidence from typing [38] and chess [8] suggests compensation is the mechanism by which experts maintain superior performance as general capacities decline. Experts acquire domain-specific compensatory skills to offset declines in other areas. Salthouse [38] postulated that older typists maintained similar performance to young typists through more extensive anticipation, which was reflected in older typists' larger eye-hand span. This compensated for their decline in finger tapping speed, choice reaction time, and performance on the digit symbol substitution test. Similarly, Charness [8] speculated that expert chess players developed a more refined move selection process to compensate for an overall search that was less extensive and slower than younger experts.

The selective maintenance account proposes that experts are able to maintain high levels of performance through sustained practice. In contrast to acquiring new skills to compensate for declines in other areas, selective maintenance asserts that the same domain specific skills that are acquired through deliberate practice can be maintained, provided that practice continues. Krampe and Ericsson [29] found the measure that correlated most strongly with performance in the older pianists was the amount of time they had spent in deliberate practice in the last 10 years. While the older experts displayed a deterioration, similar to the older amateurs in measures of general processing speed (choice RT, digit symbol substitution), older experts showed no such decline, and were equivalent to the young experts in piano-specific skills (e.g., speeded multi-finger sequencing tasks).

Common to both the compensation and selective maintenance theories is that continued practice is necessary 
in order to sustain a high level of performance [28]. Domainspecific practice appears important for maintaining skills, or facilitating the development of compensatory mechanisms as an adaptation to age-related declines. Simple accumulation of experience in the domain does not appear to be sufficient to attenuate the effects of age $[33,34]$. The older amateur pianists measured by Krampe and Ericsson [29] had 40 years of experience in music, but this in itself was not enough to prevent decline in both general and domain-specific skills. These findings are mirrored in medicine [18] and accounting [5], where performance of professionals has shown declines subsequent to the end of formal training, despite increasing years of experience in the field. It seems that staying on the job does not guarantee that performance remains intact in older age; maintaining skills requires substantial effort [28]. Of importance then are the specific activities in which experts need to engage in order to maintain a high level of achievement.

\section{The microstructure of practice}

Essentially, there are two paradoxes at work here. First, expert performers are able to sustain a high level of performance in the face of an overall decline in general capacities. Second, experts maintain this performance in spite of reduced involvement in their field. For example, the scoring average of elite golfers only deteriorated by one stroke per round (71.5 to 72.5) from the ages of 35-49, even though the number of competitive rounds played declined by almost two thirds [4]. While a reduction in competitive rounds does not necessarily indicate reduced overall involvement in the game, research into the practice habits of master level runners and swimmers showed that they train substantially less than those competing at an elite level [44].

While continued engagement in deliberate practice appears to be fundamental to sustaining performance in most domains, evidence suggests that less of this specialized practice is required in the maintenance phase than during earlier skill acquisition phases. Krampe and Ericsson [29] found that older pianists spent considerably less time engaged in deliberate practice compared to younger experts (10.8 h weekly vs. $26.7 \mathrm{~h})$ with little discernible loss in performance. The authors noted that overall time spent in music had increased - older experts spent an average of $60 \mathrm{~h} /$ week on music-related activities, which was slightly more than younger experts. Increased teaching and professional duties amongst the older experts, however, left less time for deliberate practice.

Health considerations, particularly recuperation time, may also play a role in the reduction of deliberate practice as one ages. Krampe and Charness [28] noted that deliberate practice is considered by experts to be among the most effortful of activities, and that as experts age, they must compromise between the time spent in practice and bodily constraints. Similar notions exist in the athletic realm; older athletes are often given more rest time to facilitate recuperation [44]. Tied to this notion is the belief that older athletes are more efficient in their training. Former hockey player and Olympic gold medalist (and Ph.D. in kinesiology) Therese Brisson remarked "More experienced athletes tend to train smarter and more efficiently.... I find that I can accomplish more in a 40-minute workout than a less experienced athlete can accomplish in a 3-hour session" (quoted in [42], p. 271). Older musicians also report that their practice is more efficient than when they were younger [28].

Starkes et al. [44] examined the specific training activities of master swimmers and runners and found that, in addition to reducing the number of hours, these athletes tended to narrow their training to focus on endurance activities. This narrowing generally came at the expense of all other training components. It is possible that this focus on endurance activities is the most efficient use of training time and minimizes the possibility of sustaining injuries. It is important to note, however, that runners indicated that endurance training is less effortful than other practice activities, such as speed and power drills or weight training [49]. Research on figure skaters suggests that experts will often spend the majority of their practice time rehearsing aspects of the repertoire that have already been mastered, in spite of their awareness that adding new and difficult elements to their program is a key component of continued improvement [13]. While athletes may have good intentions and know what is required to improve, they will not always engage in deliberate, effortful practice of their own accord.

Focusing on less effortful components of training may be a method of both minimizing the risk of injury and sustaining motivation after years of involvement in a particular field. There is the possibility, however, that reducing the number of hours, and a narrowing of training activities to focus on ones that are less effortful has performance consequences and explains the accelerated performance decline we see in some areas after a certain age [4, 47]. Ericsson [17] noted that most age-related decline in expert performance is not a result of an inevitable deterioration in general capacities but instead a consequence of a reduction in the frequency and intensity of practice activities. Thus, important questions include: how much practice is required to maintain performance and how might that vary depending on the demands of the activity? To what extent, and for how long, can persistent engagement in deliberate practice delay the onset of performance decline? Furthermore, is it possible that with the right kind of training, improvements are possible much later than the age of peak performance would suggest? 
The notion of compensation suggests the acquisition of new skills, or at least new subcomponents of skills, must occur in order to maintain performance. This implies that significant adaptation is possible, and even improvement given the proper training, past the age at which we might have expected performance to permanently plateau. Starkes et al. [44] detailed the case study of DR, who achieved a personal best time of $4: 20$ for the mile at age 41 . Considering that mile runners generally peak around age 25 [40], DR's performance seems even more impressive. Noteworthy is the fact that his improving performance in his 40 s corresponded with an increase in training. DR was logging $100 \mathrm{~km}$ per week when he set his personal best, approximately a $25 \%$ greater training load than when he was in his mid-20s.

Conzelmann's [10] case study demonstrated the relationship between the amount of training and performance in $5,000 \mathrm{~m}$ running. While a career best time (15.32 $\mathrm{min})$ was achieved at the age of 23, this particular athlete was still posting times of less than 16 min at the age of 57, at which point training intensity had to be curtailed due to injury factors. Of interest was the fact that these near-peak levels of performance were achieved in later life despite a virtual absence of training for a 10-year period during the athlete's 30 s.

The creation of the Champions Tour 25 years ago has extended competitive opportunities in golf. Designed for players 50 years of age and older, golfers now compete at a very highly level well into their 60 s. As a result, there have been golfers, as a group traditionally thought to peak in their early 30s [40] who have won on both the regular PGA Tour and the Senior Tour in the same year [36]. With expanded competitive opportunities and increased incentives to play and practice, older golfers are changing conceptions of what is possible in the sport. Gary Player is one such example. Considered a paragon of fitness throughout his entire career, Player continues to compete on the Champions Tour with men 20 years his junior. In the 2006 season, at the age of 71, Player's scoring average was 74.9 over 33 rounds [36]. In 2007, Player competed in his 50th consecutive Master's tournament.

Ed Whitlock is having a similar impact in long-distance running. Whitlock, at age 69 , set the record for being the oldest person to run a marathon in less than $3 \mathrm{~h}$ [44]. Now in his mid-70s, Whitlock has the only three sub-3-h performances by a septuagenarian [7]. Equally remarkable is the fact that he trains approximately $18 \mathrm{~h} /$ week, which is equivalent to the training volume reported by younger expert runners [44]. Greater attention to the microstructure of practice and the training regimens of exceptional older performers may provide insight into what is possible in later years.

Based on available evidence it appears that psychomotor and cognitive skills are more resistant to the aging process than physiologically based capacities. In their review of expert/novice differences in sport, Starkes and Deakin [43] made the distinction between hardware and software capacities. Hardware includes underlying physical abilities such as reaction time and visual acuity, while software consists of learned skills and strategies such as pattern recognition and anticipation. Differences between experts and non-experts in sport have been almost exclusively attributed to software. Although this distinction between hardware and software is largely limited to studies examining expertise development, it may also be appropriate for skill maintenance. Capacities that would be deemed as 'software' using the Starkes and Deakin categorization (e.g., anticipation as in Schorer and Baker [41] or golf putting in [3]) appear to be more resilient in the face of advancing aging than those comprised primarily of 'hardware' components (e.g., 10,000 m running time as in [44]). It may be that software skills are more readily compensated for than hardware skills.

Conclusion: skill acquisition and maintenance in an aging society

Clarence Brazier learned to read at 93 years of age [32]. He started modestly, with words like cat and rat, but has progressed to the point where he spends $2 \mathrm{~h}$ a day reading - everything from newspapers to books on history and politics. Now, at age 100, Brazier goes into seniors' homes to "visit with the young lads", telling those in their $60 \mathrm{~s}$ and 70s that "they've got 30 years of good reading ahead of them" ([29], p. A5). Given that $40 \%$ of adult Canadians fall short of being fully functionally literate, Brazier imparts an important message, and an inspiring story. For his efforts, Brazier was awarded the National Literacy Award for 2006 [32].

Research into skill acquisition and maintenance as one ages is likely to take on even greater importance, given the demographic trends in our society. With the number of adults over 65 expected to double by the year 2026 [48], and the corresponding financial pressure that this will exert on both public and private pensions [21], there may be fundamental changes required with respect to how we view retirement and 'old age'. In a sense this has already begun, with Canada abolishing mandatory retirement at age 65 . Old age security payments were first established when life expectancy was 67. Currently, life expectancy is over 80 in Canada as well as many other industrialized countries [27]. Vast numbers of people retiring at 65 may be a luxury that our society can no longer afford.

As a result, increasing attention to skill maintenance in seniors takes on added significance, as does the notion of retraining in a world where technology can change so much so quickly. Certain studies suggest that older adults benefit 
less from training than younger adults [30] and that learning rates decrease in later adulthood, particularly after age 70 [46]. These studies reinforce the notion of widespread physical and cognitive decline with age. The ability of older experts to maintain their skills in spite of declines in general processing, and in spite of reductions in the amount of time spent in practice is important from a societal and public policy standpoint. Further examination into the microstructure of training and the manner in which older experts continue to excel has wide social implications, for as Clarence Brazier has shown us, we may just be scratching the surface as to what is possible in our later years.

\section{References}

1. Allard F, Graham S, Parsaalu ME (1980) Perception in sport: basketball. J Sport Psychol 2:14-21

2. Baker J, Côté J, Abernethy B (2003) Sport-specific practice and the development of expert decision-making in team ball sports. $\mathrm{J}$ Applied Sport Psychol 15:12-25

3. Baker J, Deakin J, Horton S, Pearce GW (2007) Maintenance of skilled performance with age: a descriptive examination of professional golfers. J Aging Phys Act 15:299-316

4. Baker J, Horton S, Pearce GW, Deakin J (2005) A longitudinal examination of performance decline in champion golfers. High Abil Stud 16:179-185

5. Bedard J, Chi MTH (1993) Expertise in Auditing. Auditing 12 (Suppl.):1-25

6. Bortz WM, Bortz WM (1996) How fast do we age? Exercise performance over time as a biomarker. J Geront: Med Sci 51A: M223-M225

7. Brookes A (2005) Ed Whitlock has resounding victory in Rotterdam with another sub-3:1-0 Canada! Retrieved on October 14th, 2006 from www.torontowaterfrontmarathon.com/en/news/ Apr_11b_05.htm

8. Charness N (1981) Search in chess: Age and skill differences. J Exp Psychol: Human Perc Perform 7:467-476

9. Chi MTH, Feltovich PJ, Glaser R (1981) Categorization and representation of physics problems by experts and novices. Cog Sci 5:121-152

10. Conzelmann A (1997) Entwicklung konditioneller Fähigkeiten im Erwachsenenalter [Development of aerobic skills as adults age]. Schorndorf. Hofmann

11. Davids K, Baker J (2007) Genes, environment and sport performance: why the Nature-Nurture dualism is no longer relevant. Sports Med 37:961-980

12. Deakin JM, Allard F (1991) Skilled memory in expert figure skaters. MemCog 19:79-86

13. Deakin J, Cobley S (2003) An examination of the practice environments in figure skating and volleyball: A search for deliberate practice. In: Starkes JL, Ericsson KA (eds) Expert performance in sports. Human Kinetics, Windsor, pp 115-136

14. de Groot AD (1965) Thought and choice in Chess. Mouton, Paris

15. Elstein AS, Shulman LS, Sprafka SA (1978) Medical problem solving. Harvard University Press, Cambridge, MA

16. Ericsson KA (1996) The acquisition of expert performance: An introduction to some of the issues. In: Ericsson KA (ed) The road to excellence: The acquisition of expert performance in the arts and science, sports and games. Erlbaum, New Jersey, pp $81-106$
17. Ericsson KA (2000) How experts attain and maintain superior performance: implications for the enhancement of skilled performance in older individuals. J Aging Phys Act 8:366-372

18. Ericsson KA (2004) Deliberate practice and the acquisition and maintenance of expert performance in medicine and related domains. Acad Med 10:S70-S81

19. Ericsson AE, Krampe R, Tesch-Romer C (1993) The role of deliberate practice in the acquisition of expert performance. Psychol Rev 100:363-406

20. Galton FRS (1881) Hereditary genius: An inquiry into its laws and consequences. D. Appleton and Company, New York

21. Gladwell M (2006) What's behind Ireland's economic miracle-and GM's financial crisis? The New Yorker. Retrieved on October 15th, 2006 from www.gladwell.com/2006/2006 05 29 a risk.html

22. Helsen WF, Starkes JL, Hodges HJ (1998) Team sports and the theory of deliberate practice. J Sport Exer Psychol 20:12-34

23. Hodge T, Deakin JM (1998) Expertise in the martial arts. J Sport Exer Psychol 20:260-279

24. Hodges NJ, Starkes JL (1996) Wrestling with the nature of expertise: a sport specific test of Ericsson, Krampe and TeschRomer's (1993) theory of “deliberate practice. Int J Sport Psychol 27:400-424

25. Horn J, Masunaga $H$ (2006) A merging theory of expertise and intelligence. In: Ericsson KA, Charness N Feltovich PJ, Hoffman RR (eds) The Cambridge handbook of expertise and expert performance. Cambridge University Press, New York, pp 587-611

26. Howe MJA (1999) Genius explained. Cambridge University Press, Cambridge

27. Jackson D (2006) Some people don't always die on time. Globe and Mail, October 7, p B11

28. Krampe RT, Charness N (2006) Aging and expertise. In: Ericsson KA, Charness N Feltovich PJ, Hoffman RR (eds) The Cambridge handbook of expertise and expert performance. Cambridge University Press, New York, pp 723-742

29. Krampe RT, Ericsson KA (1996) Maintaining excellence: deliberate practice and elite performance in young and older pianists. $\mathrm{J}$ Exp Psychol: Gen 125:331-359

30. Kubeck JE, Delp ND, Haslett TK, McDaniel MA (1996) Does job-related training performance decline with age? Psychol Aging 11:92-107

31. Lehman HC (1953) Age and achievement. American Philosophical Society, Princeton

32. MacGregor R (2006) 100 years old and a man of letters. Globe and Mail, October 7, pp A4-A5

33. Meinz EJ (2000) Experience-based attenuation of age-related differences in music cognition tasks. Psychol Aging 15:297-312

34. Meinz EJ, Salthouse TA (1998) The effects of age and experience on memory for visually presented music. J Geron: Psychol Sci 53B:P60-P69

35. Owen D (2000) The chosen one. The New Yorker, Aug 21/28, 106-119

36. PGA Tour (2006) Retrieved October 10th 2006 from www. pgatour.com/players/bio/132113

37. Rabbit PMA (1977) Changes in problem-solving ability in old age. In: Birren JE, Schaie KW (eds) Handbook of the psychology of aging. Van Nostrand Reinhold, New York, pp 606-625

38. Salthouse TA (1984) Effects of age and skill in typing. J Exp Psychol: Gen 113:345-371

39. Schmidt FL, Hunter JE (1998) The validity and utility of selection methods in personnel psychology: Practical and theoretical implications of 85 years of research findings. Psychol Bull 124:264-272

40. Schultz R, Curnow C (1988) Peak performance and age among superathletes: Track and field, swimming, baseball, tennis, and golf. J Geron: Psychol Sci 43:P113-P120

41. Schorer J, Baker J (2008) Aging and perceptual-motor expertise in handball goalkeepers. Exp Aging Res (in press) 
42. Sloboda J (1976) Visual perception of musical notation: Registering pitch symbols in memory. Q J Exp Psychol 28:1-16

43. Starkes JL, Deakin JM (1984) Perception in sport: a cognitive approach to skilled performance. In: Straub WF, Williams JM (eds) Cognitive sport psychology. Sport Science Associates, New York, pp 115-128

44. Starkes JL, Weir PL, Young B (2003) What does it take for older expert athletes to continue to excel? In: Starkes JL, Ericsson KA (eds) Expert performance in sports. Human Kinetics, Windsor, pp 251-272

45. Simon HA, Chase WG (1973) Skill in Chess. Amer Sci 61:394403
46. Singer T, Lindenberger U, Baltes PB (2003) Plasticity of memory for new learning in very old age: A story of major loss? Psychol Aging 18:306-317

47. Stones MJ, Kozma A (1981) Adults trends in athletic performance. Exp Aging Res 17:269-280

48. Weir PL, Kerr T, Hodges NJ, Mckay SM, Starkes JL (2002) Master swimmers: How are they different from younger elite swimmers? An examination of practice and performance patterns. J Aging Phys Act 10:41-63

49. Young BW, Salmela JH (2002) Perceptions of training and deliberate practice of middle distance runners. Int J Sport Psychol $331: 67-181$ 